\title{
WHEN IS A PERSON WITH DEMENTIA IN NEED OF PALLIATIVE CARE? OPINIONS OF HEALTHCARE PROFESSIONALS AND UNIVERSITY STUDENTS FROM THREE SOUTH EAST EUROPEAN COUNTRIES
}

\author{
Vaitsa Giannouli ${ }^{1}$, Desislava Ivanova ${ }^{2}$, Stanislava Stoyanova ${ }^{2} \&$ Marius Drugas $^{3}$ \\ ${ }^{l}$ Bulgarian Academy of Sciences, Sofia, Bulgaria \\ ${ }^{2}$ Department of Psychology, South-West University "Neofit Rilski", Blagoevgrad, Bulgaria \\ ${ }^{3}$ Department of Psychology, University of Oradea, Oradea, Romania
}

received: 18.11.2017;

revised: 26.10.2018;

accepted: 26.11 .2018

\begin{abstract}
SUMMARY
Background: Recommendations of the European Association for Palliative Care have been proposed to strengthen the provision of palliative care and it is clear that people with dementia can benefit from palliative care, but no research so far addresses the beliefs of university students and professionals in the social, medical and other science fields in South East Europe regarding the need from palliative care. The objective of this study is to explore when students and professionals consider a person with dementia in need of palliative care and to compare their opinions in three South East European countries.

Subjects and methods: An anonymized questionnaire was used based on van Riet Paap et al. (2015) case-vignette. A sample of 1287 participants (student nurses, professional nurses, psychology students, professional psychologists, student doctors, professional doctors, and students and professionals from other non-relevant to medical and social care sciences) was examined in Greece, Bulgaria and Romania.

Results: The open responses to the "when" question revealed the categories: after her diagnosis/after the first symptoms; when she and her family cannot cope; at the advance of symptoms; all the time; when she behaves aggressively; I am not sure/there is no specific point. Unexpectedly, age, professional status and field of studies were not found to be significant predictors, but only the country of origin was found to contribute to the differences in the participants' answers regarding the start of palliative care.

Conclusion: Although professional-student status and relevancy of subject did not predict opinions, the country of origin predicted controversies for the proposed time point of considering a person with dementia in need of palliative care.
\end{abstract}

Key words: palliative care - dementia - healthcare professionals - university students - opinions - South East Europe

$* * * * *$

\section{INTRODUCTION}

The number of people suffering from dementia worldwide is rapidly growing (Minett \& Brayne 2016), while the need for psychiatrists to work with patients and families living with chronic life-threatening illnesses has never been greater (Irwin \& Ferris 2008). Palliative care is "an approach that improves the quality of life of patients and their families facing the problems associated with life-threatening illness, through the prevention and relief of suffering by means of early identification and impeccable assessment and treatment of pain and other problems, physical, psychosocial and spiritual" (World Health Organization 2013). A palliative approach to dementia care involves supporting both the person with dementia and their family. It seeks to address and relieve the pain, distress and discomfort associated with advancing dementia and invites the person and family to participate in making decisions about future care needs and where it is best delivered. Palliative dementia care actively treats distressing symptoms (physical or psychological or emotional), to optimise the quality of life for the person with dementia, and their family, knowing that he underlying cause cannot be cured (ACH Australia 2009).
Although appropriate palliative care is claimed to be important in the management of needs and preferences of people with dementia and their family members, as it improves the quality of life (Birch \& Stokoe 2010), access to palliative care services for people with dementia is less defined than for patients with other types of diseases (Ouldred \& Bryant 2008).

Professionals in dementia care often lack the necessary skills to anticipate the changing palliative care needs of a person with dementia (Ouldred \& Bryant 2008, Harris 2007, Bekkema et al. 2014). Therefore, people with dementia are more frequently hospitalized and often receive burdensome interventions (Brown et al. 2013). Moreover, compared to patients with other life-threatening diseases, they are less likely to receive advance care planning (Harris 2007), are less frequently referred to palliative care teams or hospice care (Harris 2007) and more often experience symptoms for a longer period of time (McCarthy et al. 1997). It remains generally unexplored for professionals, students and laypeople, in which way they identify if and when a person with dementia is in need of palliative care, thus transforming the above two questions into important challenges in delivering effective palliative care for older people with dementia (Birch \& Draper 2008). 
A survey in Europe revealed that palliative care services for people with dementia are lacking, as well as there is a lack of support for careers of people with dementia in the final stage of life (Bernardo et al. 2008).

The European Association for Palliative Care in order to approach this problem has published a white paper which defines the complex issue of palliative care in dementia (van der Steen 2013). One of the recommendations is to consider the time point of the diagnosis of dementia as the starting point of palliative care (van der Steen 2013). Another opinion is that palliative cares facilitate suffering of ill people whose health status can only become worse (Stavru n.d.). However, there is still an ongoing discussion about the palliative care in dementia in various western countries (mainly healthcare employees in long-term care settings-nursing homes in France, Germany, Italy, Netherlands, Norway, and Poland) (van Riet Paap et al. 2015), while no relevant research has been conducted yet on the issue of the time of considering a person with dementia in need of palliative care in non-central European countries.

The main objective of this cross-cultural study was to examine the contribution of professional expertise, student status and country of origin to opinions in three nearby South East European countries regarding the complex, but everyday issue of if-when a person with dementia is considered to be in need of palliative care. We supposed some cross-cultural differences in the opinions regarding the start of palliative care, in spite of the recommendations of the European Association for Palliative Care (EAPC) (van der Steen 2013), because of the different history and trajectory of palliative care services in each country, and because of the crosscultural differences found in some other European countries (van Riet Paap et al. 2015).

\section{Palliative cares in Bulgaria}

Palliative cares in Bulgarian health care system are considered to be provided for elderly people and people with impairments in treatment institutions for hospital and extra-hospital care, as well as in hospices, for diminishing their suffering from illnesses that cannot be recovered with medicaments ("Council of Ministers of Republic of Bulgaria" 2014). Palliative cares treat some symptoms and pain, so they do not treat actively the disease, but in fact palliative cares are provided in a lot of hospitals for active treatment in Bulgaria, whilst in EU palliative cares are provided mainly in hospices by volunteering specialists. Financing palliative cares in Bulgaria is provided only for oncologic patients in some hospitals for active treatment in Bulgaria ("Council of Ministers of Republic of Bulgaria” 2014). Bulgarian legislation provides for palliative cares for oncologic patients in their extra-hospital medical assistance ("Republic of Bulgaria State Gazette" 2014). Palliative cares are provided in the hospices for patients in the terminal phase of the disease for reducing the symp- toms and the pain, giving emotional support for the patients and their relatives ("Municipality of Gabrovo, Bulgaria" 2016).

Bulgarian National health strategy 2020 stipulates that all elderly people should have equal access to health services, including palliative cares given on spot in medical institutions and at home, by medical staff whose functions are broaden to provide long-term palliative cares and these palliative cares should be guaranteed by means of new financial mechanisms ("Bulgarian Ministry of Health" 2015).

Palliative cares were provided in Bulgaria in 2013 only for people suffering from cancer disease. The main problems in Bulgarian palliative care are limited experience and skills in palliative care (in spite of the fact that first palliative care training courses were offered in Bulgaria in 1992) and limited finance - only 20 days care per six months is guaranteed for oncologic patients (Centeno et al. 2013). Palliative cares are provided in hospices mainly by nurses. About $1 / 3$ rd of the Bulgarian hospices provide both inpatient palliative care and home-based palliative care for terminally-ill patients (Centeno et al. 2013).

Some Bulgarian scientists have recommended palliative care for other kind of diseases, too. Palliative cares should be applied in chronic neurological diseases, including dementia, for patients and their families for improving their quality of life by a multidiscipline team consisting of a neurologist, some other specialists physicians, a nurse, a psychologist, a kinesiotherapist, a social worker and a clergyman (Nisimov 2015).

Contemporary palliative cares are recently developed in neurological practice. Traditionally, palliative cares were applied in the terminal stage of multiple sclerosis, but the contemporary strategy includes palliative cares since the beginning of the disease that integrate treatment of the symptoms, supportive treatment, neurological rehabilitation, psychological and social support, and spiritual support by a multidiscipline team consisting of a neurologist, some other specialists physicians, a nurse, a psychologist, a kinesiotherapist, a social worker and a clergyman (Chohadzhieva \& Nisimov 2015).

Palliative cares in Bulgaria are provided mainly in hospices and by home care teams ("EAPC Task Force on the development of Palliative Care in Europe Bulgaria" 2006).

In Bulgarian health system, palliative cares are provided in medical institutions for hospital and extrahospital assistance, as well as in hospices by a multidiscipline team, including specialists in oncology and health cares, social workers, psychiatrist, psychologists, and clergymen ("More 2015 National Expert Board" 2015).

The state's health policies should be focused on recognition of end-stage dementia as requiring palliative care; providing access to palliative care services for 
people with dementia; giving sufficient financial remuneration and attractive working conditions for healthcare professionals who work in palliative care; promoting research into palliative care for people with dementia (Bernardo et al. 2008).

Palliative care is the best option for people with endstage dementia, but only a half of 31 countries in 2009 reported on some degrees of palliative care rights or guidelines (including in Bulgaria, but not such findings in Greece), and even where a right to palliative care exists, it didn't follow that palliative care was received. In Bulgaria, there is a right to palliative care and yet it is infrequently realized ("Healthcare decision making in Europe for people with dementia" 2010).

\section{Palliative cares in Greece}

In Greece there are no officially established palliative care centers and the provision of palliative care is based on the voluntary services of various specialties of health professionals, such as anaesthesiologists, oncologists, psychologists, nurses etc. (World Health Organization 2011). Thus, research regarding palliative care services in primary, secondary and tertiary health care need to be developed and expanded. In addition to that, there is no support from the government and the people are not very well informed about palliative care, especially for the group of patients that are elders suffering from mental health disorders and/or dementia (Burgio, Gaugler \& Hilgeman 2016, Giannouli 2017). Although palliative cares in Greece is provided in the pain centers of Anaesthesia Departments at hospitals and by specialists and volunteers, the already large and increasing demands and the poor supply, as is the case in Greece (Choy 2017), render necessary the initiatives for research and palliative care training courses (Centeno et al. 2013).

\section{Palliative cares in Romania}

From the strong religious aspects of medical and social care from the $18^{\text {th }}$ century to the diversification of medical care at the beginning of the $20^{\text {th }}$ century, Romania witnessed a growing interest for the terminally ill. Nevertheless, the first specialized palliative care centers were created only after the political movements in the $1990 \mathrm{~s}$, often with the help of foreign funding programs (Dumitrescu et al. 2003), and without any support from the authorities (Enache et al. 2013).

The first efforts to offer palliative care were the results of non-governmental organizations (e.g., The „St. Lawrence” Hospice, for children with AIDS, or „Hospice Casa Sperantei” Foundation, for patients with terminal cancer), financially supported by foreign individuals or organizations.

The growing awareness of the need for specialized care, combined with the pressure to comply with the European norms, led eventually to the recognition of the palliative care as a special competence in 1999, by the
Ministry of Health, and two years later the first ten specialists in palliative care were confirmed (Dumitrescu et al. 2003). Spiritual support was generally offered by priests and only by a few psychologists, with no special training (Enache et al. 2013).

In 2003, the Ministry of Health allowed individuals (specialists) or organizations to provide care at home, and by the end of the year 29 centers for palliative care functioned in Romania, 7 of them being hospitals (Dumitrescu et al. 2003).

Nevertheless, the Health Law 95/2006 (still functioning today) didn't include references to the palliative care, and the services for these patients were slowly settled as for chronic ill patients or with cancer (Enache et al. 2013). The updates for the mentioned Health Law and some Government orders corrected the situation to this day; the legislative improvements included the funding mechanisms for the reimbursement of palliative care services through the health insurance funds, the review of opioid policy, and the quality standards of care (Mosoiu et al. 2017).

Romania was included by Connor \& Bermedo (2014) in their ,Global Atlas of Palliative Care at the End of Life" among the countries where hospice care services are at a stage of advanced integration into mainstream service provision. This group of countries is characterized by: ,the development of a critical mass of palliative care; activism in a wide range of locations; comprehensive provision of all types of palliative care by multiple service providers; broad awareness of palliative care on the part of health professionals, local communities and society in general; unrestricted availability of morphine and all other strong pain-relieving medicines; substantial impact of palliative care upon policy, in particular upon public health policy; the development of recognised education centres; academic links forged with universities; and the existence of a national palliative care association" (p. 39). Some other European countries included in this category were Austria, Belgium, France, Germany, Italy, Norway, Poland, Sweden, and Switzerland.

For hospitals, the accreditation requirements in Romania specify that palliative care is aimed at patients suffering from progressive chronic diseases and their families and is meant to improve the quality of their life by reducing suffering (...); it is provided within an appropriate environment, as close as possible to the family" (Vajasdi \& Chiriac 2017). The eligible patients for hospitalization are analyzed by a multidisciplinary committee, including a physician, a clinical pharmacist, nurses, nurse aids, a social worker, a psychologist and a spiritual counselor. They are often aided by volunteers. Today, the over-utilization of palliative care wards and the long waiting lists for these services facilitated the apparition of an increasing number of private care providers and the reinforcement of family care (Vajasdi \& Chiriac 2017). By the end of 2015, Mosoiu et al. (2017) identified 115 specialist palliative care services 
(78 palliative care inpatient units, 24 home-based palliative care services, 5 outpatient palliative care clinics, 4 day care centers and 4 hospital support teams).

Still, the lack of funding, the deficiencies in the illness preventions policies, corruption, and the general condition of the Romanian hospitals are other variables that may lead to home care. In this situation, the family members are those who deliver palliative care services, but local palliative care teams may be involved (depending on the financial resources), including nurses, social workers or specialists in medicine or psychology. The tradition still is that people die at home, taken care for by family members. Patients and their families often prefer so, because of the family ties and the higher costs of being hospitalized (van den Heuvel \& Olăroiu 2006). This system may function well and it may deliver quality care, as shown by the project „Palliative care in Romania" conducted by Dumitrescu (2006). As such, although the palliative care in Romania has developed progressively (but slowly), the system of services is still below the needed level of functioning. Facilities and expertise should be improved, together with the number of palliative care centers.

\section{SUBJECTS AND METHODS}

\section{Participants/Setting}

One thousand two hundred eighty-seven participants were examined in three countries in a cross-sectional selfreport research design. 419 came from Northern Greece (305 women; 380 not having a relative diagnosed with dementia; 60 psychology students, 48 professional psychologists, 50 student doctors, 61 professional doctors-psychiatrists, 49 student nurses, 50 professional nurses, 50 other professionals and 51 students of non-relevant sciences; $\mathrm{M}_{\mathrm{age}}=29.51, \mathrm{SD}_{\mathrm{age}}=9.56$; and for the professionals $\mathrm{M}_{\text {years of professional working experience }}=8.34$, $\mathrm{SD}_{\text {years of professional working experience }}=7.35$ ), 400 from Romania (291 women; 354 not having a relative diagnosed with dementia; 50 psychology students, 50 professional psychologists, 50 student doctors, 50 professional doctors, 50 student nurses, 50 professional nurses, 50 other professionals and 50 students of non-relevant sciences; $\quad \mathrm{M}_{\mathrm{age}}=28.82, \quad \mathrm{SD}_{\mathrm{age}}=9.44 ;$ and for the professionals $\quad \mathrm{M}_{\text {years of professional working experience }}=5.66$, $\left.\mathrm{SD}_{\text {years of professional working experience }}=8.14\right)$, and 468 participants from Southern Bulgaria (349 women; 408 not having a relative diagnosed with dementia; 71 psychology students, 51 professional psychologists, 59 student doctors, 55 professional doctors, 61 student nurses, 58 professional nurses, 51 other professionals and 62 students of non-relevant sciences; $\mathrm{M}_{\mathrm{age}}=31.68, \mathrm{SD}_{\mathrm{age}}=11.51$; and for the professionals $\mathrm{M}_{\text {years of professional working experience }}=15.14$, $\mathrm{SD}_{\text {years of professional working experience }}=9.96$ ), participated voluntarily in this cross-cultural study. All participants were equated regarding their demographics. Although this procedure provided a convenience sample that could not be considered representative of students/professionals in the three countries, for a pilot study it is a cost-effective way to reach participants and gather data for the first time from three little investigated social and cultural environments in the European Union. Data collection was conducted simultaneously (November 2016-July 2017).

\section{Inclusion/exclusion criteria}

Inclusion criteria were as follows: aged 18 years and older, being a university student registered at a public university or a licensed professional (medical doctor, psychologist, nurse or other professional - for example social worker, pharmacist) working at private or public healthcare settings at the time of the questionnaire administration, and having no confirmed past or current diagnosis of neurologic and psychiatric disease.

\section{Data collection}

A case-vignette describing a person with dementia was taken from another study (van Riet Paap et al. 2015): «Mrs. White is 83 years old. She has been married for 56 years to Charles. They have one child, Lucy, who is 47 , and who keeps in regular contact with them. Mrs. White was diagnosed with dementia about 9 years ago. Until recently, she lived with her husband in a house in the country. Because Mrs. White can get quite aggressive when she does not understand what is going on, her husband can no longer deal with her at home. Therefore Mrs. White recently moved to a nursing home».

The above was translated in Greek, Romanian and Bulgarian, and administered along with a demographic questionnaire. Two open-ended questions were administered: 1) Please explain if you would consider Mrs. White as a person in need of palliative care?, 2) Please explain when you would consider Mrs. White as a person in need of palliative care?. After that in another paper, participants were administered three closed-ended questions: 3) Palliative care should start early in the disease trajectory? (yes-no), 4) Palliative care should start when clinical symptoms of advanced dementia are present? (yes-no), and 5) Palliative care should start when curative treatment for co-morbidities has no longer a beneficial effect? (yes-no). This case-vignette explicitly excludes clinical details of the depicted subject in order to stimulate full-length responses for the open-ended question.

The researchers translated the answers of the participants to the open question of the vignette into English, following the analyses as in the original paper (van Riet Papp et al. 2015). The open-ended answers to the 'when' question were used along with the answers to the 'when' close-ended questions in order to examine if there were any other time points reported other than the three identified by previous research (van Riet Papp et al. 2015). 
Data were processed statistically by means of SPSS 18 applying descriptive statistics, logistic regression for establishing the predicting variables of the opinions regarding the appropriate start of palliative care, and chi-square for comparing the frequency of opinions.

\section{RESULTS}

The "if" question received a cross-culturally homogenous positive response (1187/1287). Qualitative analysis revealed that clearly the most common reported time points for palliative care were: after her diagnosis/after the first symptoms $(\mathrm{N}=366)$; when she and her family cannot cope $(\mathrm{N}=117)$; at the advance of symptoms $(\mathrm{N}=59)$; all the time $(\mathrm{N}=25)$; when she behaves aggressively $(\mathrm{N}=81)$; I am not sure/there is no specific time point $(\mathrm{N}=15)$; when deterioration is obvious and nothing else works $(\mathrm{N}=10)$; when doctors decide in a clinic/nursing home offering a complex care $(\mathrm{N}=4)$. The rest of the responses-answers were too ambiguous, and they could be included in multiple categories/time points, thus were not included as clear responses in the qualitative analyses.

Logistic regression was used with the dichotomous 'yes/no' answers to the close-ended "if" and "when" questions as dependent variables and country of origin, student-professional status, relevancy of subject of studies/work, age, and having some relatives with dementia were used as independent variables. Data analysis revealed that only having a relative or not suffering from dementia $(b=-1.151, S E=0.522, \quad W a l d=4.867$, $\mathrm{p}=0.027$ ) predicted the odds of a 'yes/no' answer regarding the Mrs. White as a person is in need of palliative care. Only the job status predicted whether or not palliative care should start early in the disease trajectory $(\mathrm{b}=-0.094, \mathrm{SE}=0.026$, Wald $=12.819, \mathrm{p}<0.001)$. Again job status $(b=0.087, \mathrm{SE}=0.026$, Wald $=11.593, \mathrm{p}<0.001)$ as well as the country of origin $(b=0.203, S E=0.072$, Wald $=7.994, \mathrm{p}=0.005)$ predicted the odds of a 'yes/no' answer regarding whether or not palliative care should start when clinical symptoms of advanced dementia were present. Finally, for the last question regarding whether palliative care should start when curative treatment for co-morbidities has no longer a beneficial effect, country of origin $(b=-0.140, \mathrm{SE}=0.070, \mathrm{Wald}=3.966, \mathrm{p}=0.046)$ and age predicted the yes/no response origin $(b=-0.016$, $\mathrm{SE}=0.006$, Wald $=8.053, \mathrm{p}=0.005$ ).

We conducted a Chi-Square test to test for associations between the country of origin and the decision to employ palliative care early in the disease trajectory, and we found that the association was statistically significant: $\chi^{2}(2)=11.75 ; p=0.003$. The Bulgarians reported in a smaller count than expected that palliative care should start early in the disease trajectory (std. residuals $=-2.0$ ). The crosstabulation results are presented in Table 1.

Table 1. Crosstabulation results (Country*palliative care should start early in the disease trajectory)

\begin{tabular}{|c|c|c|c|c|c|}
\hline & & & Yes & No & Total \\
\hline \multirow[t]{9}{*}{ Country } & Greece & Count & 244 & 175 & 419 \\
\hline & & Expected Count & 266.6 & 152.4 & 419 \\
\hline & & Standard Residual & -1.4 & 1.8 & \\
\hline & Bulgary & Count & 324 & 144 & 468 \\
\hline & & Expected Count & 297.8 & 170.2 & 468 \\
\hline & & Standard Residual & 1.5 & -2.0 & \\
\hline & Romania & Count & 251 & 149 & 400 \\
\hline & & Expected Count & 254.5 & 145.5 & 400 \\
\hline & & Standard Residual & -0.2 & 0.3 & \\
\hline \multirow[t]{2}{*}{ Total } & & Count & 819 & 468 & 1287 \\
\hline & & Expected Count & 819 & 468 & 1287 \\
\hline
\end{tabular}

Table 2. Crosstabulation results (Country*palliative care should start when clinical symptoms of advanced dementia are present)

\begin{tabular}{|c|c|c|c|c|c|}
\hline & & & Yes & No & Total \\
\hline \multirow[t]{9}{*}{ Country } & Greece & Count & 283 & 136 & 419 \\
\hline & & Expected Count & 245.1 & 173.9 & 419 \\
\hline & & Standard Residual & 2.4 & -2.9 & \\
\hline & Bulgary & Count & 238 & 230 & 468 \\
\hline & & Expected Count & 273.8 & 194.2 & 468 \\
\hline & & Standard Residual & -2.2 & 2.6 & \\
\hline & Romania & Count & 232 & 168 & 400 \\
\hline & & Expected Count & 234.0 & 166.0 & 400 \\
\hline & & Standard Residual & -0.1 & 0.2 & \\
\hline \multirow[t]{2}{*}{ Total } & & Count & 753 & 534 & 1287 \\
\hline & & Expected Count & 753 & 534 & 1287 \\
\hline
\end{tabular}


Table 3. Crosstabulation results (Country*palliative care should start when curative treatment for co-morbidities has no longer a beneficial effect)

\begin{tabular}{|c|c|c|c|c|c|}
\hline & & & Yes & No & Total \\
\hline \multirow[t]{9}{*}{ Country } & Greece & Count & 220 & 199 & 419 \\
\hline & & Expected Count & 217.2 & 201.8 & 419 \\
\hline & & Standard Residual & 0.2 & -0.2 & \\
\hline & Bulgary & Count & 209 & 257 & 466 \\
\hline & & Expected Count & 241.5 & 224.5 & 466 \\
\hline & & Standard Residual & -2.1 & 2.2 & \\
\hline & Romania & Count & 237 & 163 & 400 \\
\hline & & Expected Count & 207.3 & 192.7 & 400 \\
\hline & & Standard Residual & 2.1 & -2.1 & \\
\hline \multirow[t]{2}{*}{ Total } & & Count & 666 & 619 & 1285 \\
\hline & & Expected Count & 666 & 619 & 1285 \\
\hline
\end{tabular}

We also conducted a Chi-Square test to test for associations between the country of origin and the decision to employ palliative care when the clinical symptoms of advanced dementia were present, and we found that the association was statistically significant: $\chi^{2}(2)=25.42$; $\mathrm{p}<0.005$. The Greeks were mostly in favor of employing palliative care when the advanced symptoms manifested (std. residuals $=-2.4$ ). The crosstabulation results are presented in Table 2.

Finally, we conducted a Chi-Square test to test for associations between the country of origin and the decision to employ palliative care when curative treatment for co-morbidities has no longer a beneficial effect, and we found that the association was statistically significant: $\chi^{2}(2)=17.99 ; p<0.005$. The Romanians were mostly in favor of employing palliative care in this situation $(\mathrm{std}$. residuals $=2.1$ ). The crosstabulation results are presented in Table 3.

\section{DISCUSSION}

Healthcare professionals in France, Germany, Italy, Netherlands, Norway, and Poland have different opinions regarding the time point when to consider a person with dementia in need of palliative care (van Riet Paap et al. 2015), but still relevant opinions in other European countries are not explored. This study addresses the opinions of professionals, as well as university students from Greece, Bulgaria and Romania regarding dementia and palliative care. This is the first study in which we get insights about the cross-cultural differences between Greeks, Bulgarians and Romanians at defining the starting point of palliative care in people with dementia. Three time points regarding the need for palliative care are generally found through open-ended and close-ended questions, namely 1) early at the beginning of dementia, 2) when clinical symptoms of dementia are present, and 3) when treatment has no longer a beneficial effect and the family cannot cope. The implications for practice, theory and policy for mental health professional are numerous. The data reveal that there are not similar opinions across students and professionals separately in each country. Marked differences across the three countries were found regarding Greeks believing that palliative care should not start early in the disease trajectory, Bulgarians believing that palliative care should start early in the disease, and Romanians being mostly in favor of employing palliative care when curative treatment for co-morbidities has no longer a beneficial effect. European recommendations of considering the time point of the diagnosis of dementia as the starting point of palliative care should be made known to the professionals, as well as the public in these three countries.

Although there was a contribution of students-professionals status to the type of answer, as it was expected because direct knowledge and experience of dementia and patient care can shape different views, it is interesting that healthcare professionals (psychologists, nurses) did not differentiate in their opinions in contrast to a previous study (van Riet Papp et al. 2015). The homogeneity in the responses of the professionals may be due to cultural factors that dictate a specific approach or because of the specific educational practices, which shape opinions in the three countries.

An interesting finding was that there was a clear differentiation between the participants from the three countries regarding not whether palliative care should or should not be given (if question), but regarding the moment to start palliative care in the disease trajectory of a person with dementia. These findings have implications relating to palliative care clinical practice and policy - special educational programs on this matter based on possible social-cultural factors.

\section{CONCLUSIONS}

The objective of this study was to explore when students and professionals consider a person with dementia in need of palliative care and to compare their opinions in three South East European countries. The professional-student status and the relevancy of subject did not predict opinions, but the country of origin predicted controversies for the proposed time point of considering a person with dementia in need of palliative care. 
Interdisciplinary palliative care services have been rapidly expanding in health care settings over the past 10 years, particularly through the establishment of interdisciplinary palliative care teams (Kasl-Godley et al. 2014). The implementation of good quality palliative care in dementia leads to the recommendation that education of students, as well as professionals, and even laypeople should be related to improvement of palliative care policy and service delivery for people with dementia. Future research should further explore the beliefs of other healthcare professionals in different countries inside and outside Europe.

\section{Acknowledgements:}

\section{FUNDING}

The author(s) received no financial support for the research, authorship, and/or publication of this article.

\section{Conflict of interest: None to declare.}

\section{Contribution of individual authors:}

Vaitsa Giannouli: responsible for the data collection in Greece; analyzed the data; drafted the first version of the manuscript; reviewed draft versions of the manuscript and approved the final manuscript.

Desislava Ivanova: responsible for the data collection in Bulgaria; analyzed the data; provided extensive feedback to draft versions of the manuscripts; reviewed draft versions of the manuscript and approved the final manuscript

Stanislava Stoyanova: responsible for the data collection in Bulgaria; analyzed the data; provided extensive feedback to draft versions of the manuscripts; reviewed draft versions of the manuscript and approved the final manuscript.

Marius Drugas: responsible for data collection in Romania; analyzed the data; provided extensive feedback to draft versions of the manuscripts; reviewed draft versions of the manuscript and approved the final manuscript.

\section{References}

1. ACH Group, Inc. Research and Development Department, Adelaide, South Australia: Australia 2009. Retrieved in November 2017, from http://achgroup.org.au/informationand-advice/information-guide-2017-2/information-guidesouth-australial

2. Bekkema $N$, de Veer AJE, Albers G, Hertogh CMPM, Onwuteaka-Philipsen BD, Francke AL: Training needs of nurses and social workers in the end-of-life care for people with intellectual disabilities: a national survey. Nurse Educ Today 2014; 34:494-500

3. Bernardo A, Cosgrave M, Gove D, Jansen S, Martensson B, Pointon B, Sparr S, Tudose C, Holmerova I: An insight into good end-of-life care for people with dementia and their carers. A summary of a European workshop on ethics and interview with Ulla Schmidt, German Minister for Health. Dementia in Europe 2008; 2:14-15
4. Birch D \& Draper J: A critical literature review exploring the challenges of delivering effective palliative care to older people with dementia. J Clin Nurs 2008; 17:1144-63

5. Birch D \& Stokoe D: Caring for people with end-stage dementia. Nurs Older People 2010; 22:31-6

6. Brown MA, Sampson EL, Jones L, Barron AM: Prognostic indicators of 6- month mortality in elderly people with advanced dementia: a systematic review. Palliat Med 2013; 27:389-400

7. Bulgarian Ministry of Health: Natsionalna zdravna strategia 2020 [National health strategy 2020]. 2015. Retrieved in February 2017, from http://www.parliament.bg/ pub/cW/20151120030041NZS-2020.pdf

8. Centeno C, Lynch T, Donea O, Rocafort J, Clark D: EAPC atlas of palliative care in Europe 2013 - Full edition. Milan: EAPC Press, 2013

9. Chohadzhieva $N$ \& Nisimov I: Miasto I rolia na meditsinskata sestra, prilagashta paliativni grizhi pri mnozhestvena skleroza [Place and role of the nurse applying palliative cares in multiple sclerosis]. Bulgarian Neurology 2015; 16(Suppl 1):112

10. Choy CHL: International access to palliative care: the need to improve. Annals of Palliative Medicine 2017; 6:S99-S101

11. Connor SR, Bermedo MCS: Global atlas of palliative care at the end of life. London: Worldwide Palliative Care Alliance, 2014

12. Council of Ministers of Republic of Bulgaria: Natsionalna strategia za dalgosrochna grizha [National strategy for long-term health]. 2014. Retrieved in February 2017, from http://www.strategy.bg/StrategicDocuments/View.aspx?la $n g=b g-B G \& I d=882$

13. Dumitrescu L: Palliative care in Romania. University of Groeningen, Groeningen, 2006

14. Dumitrescu L, van den Heuvel W, Olăroiu M, Bogdan C, Moisa C: Îngrijirea paliativă - intre trecut si viitor [Palliative care-Between past and future]. Revista Medicală Română 2003; XLX:153-159. Retrieved in October 2017 from http://www.rug.nl/research/portal/files/2862667/02_c2.pdf

15. EAPC Task Force on the development of Palliative Care in Europe - Bulgaria: 2006. Retrieved in February 2017, from http://www.eapcnet.eu/LinkClick.aspx?fileticket $=$ 6sL6S08qHCw\%3D\&tabid $=634$

16. Enache M, Gramma R, Dumitras $S$, Moisă $S$, Iov C, Ioan B: A comparative study of the palliative care in Romania and France. Postmodern openings 2013; 4:159-170. Retrieved November 2017 from http://postmodernopenings.com/wpcontent/uploads/2013/04/11-A-Comparative-Study.pdf

17. Giannouli V: Alzheimer's disease: psychosocial dimensions of a modern plague? Encephalos 2017; 55:33-8

18. Harris D: Forget me not: palliative care for people with dementia. Postgrad Med J 2007; 83:362-6

19. Healthcare decision making in Europe for people with dementia: Dementia in Europe 2010; 5:13-7

20. Burgio LD, Gaugler JE, Hilgeman MM (Eds.): The spectrum of family caregiving for adults and elders with chronic illness. Oxford University Press, Oxford, 2016

21. Irwin SA \& Ferris FD: The opportunity for psychiatry in palliative care. Can J Psychiatry 2008; 53:713-24

22. Kasl-Godley JE, King DA \& Quill TE: Opportunities for psychologists in palliative care: working with patients and families across the disease continuum. Am Psychol 2014; 69:364 
23. McCarthy M, Addington-Hall J, Altmann D: The experience of dying with dementia: a retrospective study. Int $J$ Geriatr Psychiatry 1997; 12:404-9

24. Minett $T$ \& Brayne, $C$ : Epidemiology of dementia. In: Husain $M \&$ Schott JM (eds) Oxford textbook of cognitive neurology and dementia, 211-220. Oxford University Press, 2016

25. More 2015 National Expert Board: Psihosotsialna podkrepa i rehabilitatsia $v$ onkologiata. Klinichno rakovodstvo, osnovano na dokazatelstva [Psycho-social support and rehabilitation in onclology. Clinical evidence-based guide]. Varna, 2015. Retrieved in February 2017, from http://www.more-conference.com/media/pdf/Bulgarian Psychosocial_Oncology_Guidelines_MOPE_2015.pdf

26. Mosoiu D, Mitrea N, Dumitrescu M: Palliative care in Romania. J Pain Symptom Manage. 2017; 17, in press. doi: 10.1016/j.jpainsymman.2017.03.036

27. Municipality of Gabrovo, Bulgaria: Plan za razvitie na sotsialnite uslugi v obshtina Gabrovo za 2017 godina [Plan for development of social services in municipality of Gabrovo for 2017]. 2016. Retrieved in February 2017, from http://www.gabrovo.bg/files/OBS/R/310316/65.1.pdf

28. Nisimov I: Paliativni grizhi v nevrologiata [Palliative cares in neurology]. Bulgarian Neurology 2015, 16(Supplement 1):67

29. Ouldred E \& Bryant C: Dementia care. Part 3: end-of-life care for people with advanced dementia. Br J Nurs 2008; 17:308-14

30. Republic of Bulgaria State Gazette: Natsionalna zdravnoosiguritelna kasa dogovor RD-NS-01-4 from 18 dekemvri 2013 za priemane na obemi i tseni na meditsinskata pomosht za 2014 mezhdu Natsionalnata zdravnoosiguritelna kasa i Balgarskia lekarski saiuz [National health insurance fund contract RD-NS-01-4 from December 18, 2013 about adopting the volumes and prices of medical assistance in 2014 between the National health insurance fund and Bulgarian Medical Association]. Issue 3, 10 January 2014; 100

31. Stavru S (n.d.): Mediko-pravni problem na smartta - poniatie i ustanoviavane [medical and juridical problems of death - notion and establishment]. Retrieved in February 2017, from http://ebox.nbu.bg/med13/ne14/03.\% 20Medikopravni\%20vaprosi $\% 20$ na\% 20 smarta\%20\%20poniatie\%20i\%20ustanoviavane.pdf

32. Vajasdi $H \&$ Chiriac ND: Analysis of characteristics of palliative care services in Romania versus care need based on the analysis of hospital admissions to palliative care wards during 2014-2016. Management in Health $2017 ; 21: 14-22$

33. van de Heuvel $W$ \& Olăroiu M: Palliative care in Romania: needs and rights. Romanian Journal of Bioethics 2008; 6:63-8

34. van der Steen JT, Radbruch L, Hertogh CM et al.: White paper defining optimal palliative care in older people with dementia: a Delphi study and recommendations from the European association for palliative care. Palliat Med 2013; 28:197-209

35. van Riet Paap J, Mariani E, Chattat R, et al.: Identification of the palliative phase in people with dementia: a variety of opinions between healthcare professionals. BMC Palliative Care 2015; 14:56

36. World Health Organization: WHO definition of palliative care. 2013. Retrieved in November 2017, from http://www.who.int/cancer/palliative/definition/en/

37. World Health Organization: Palliative care for older people: better practices. Denmark, 2011

Correspondence:

Vaitsa Giannouli, BSc, MSc, PhD

Bulgarian Academy of Sciences, Acad. G.

Bonchev str., bl. 23, 1113 Sofia, Bulgaria

E-mail:giannouliv@hotmail.com 